\title{
Triple Targeting of Human IMPDH and Both RdRps of SARS-CoV-2 and Rhizopus Oryzae: An in Silico Perspective
}

Abdel_moniem S Hassan

Fayoum University

Abdo A Elfiky ( $\square$ abdo@sci.cu.edu.eg )

Cairo University https://orcid.org/0000-0003-4600-6240

Alaa Elgohary

Cairo University

\section{Research Article}

Keywords: Mucormycosis, SARS-CoV-2, computational drug design, Nucleotide inhibitors, RdRp, IMPDH

Posted Date: September 3rd, 2021

DOI: https://doi.org/10.21203/rs.3.rs-863321/v1

License: (c) (i) This work is licensed under a Creative Commons Attribution 4.0 International License.

Read Full License 


\section{Abstract}

Mucormycosis has been reported in many regions associated with SARS-CoV-2 infections during the past few months. The viral RNA-dependent RNA polymerase (RdRp) is a crucial protein target in viral and fungal pathogens. Molecular docking combined with molecular dynamics simulation (MDS) is utilized to test nucleotide-based inhibitors against the RdRps of SARS-CoV-2 solved structure and Rhizopus oryzae RdRp model built in silico. Additionally, the human Inosine monophosphate dehydrogenase (IMPDH) was targeted by the same inhibitors. The results reveal a comparable binding affinity of four nucleotide derivatives compared to remdesivir and sofosbuvir against both IMPDH and the RdRps of SARS-CoV-2 and Rhizopus oryzae, the main causing agent of mucormycosis. The binding affinities are calculated using different conformations of the RdRps after $100 \mathrm{~ns}$ MDS and trajectories clustering. The present study suggests the triple inhibition potential of four nucleotide inhibitors against SARS-CoV-2 \& R. oryzae RdRps and the human IMPDH, while experimental validation is yet to be performed.

\section{Introduction:}

Severe Acute Respiratory Syndrome Coronavirus 2 (SARS-CoV-2) and its associated pneumonia (COVID19) caused health and economic burdens during the last two years. The currently developed pandemic of Mucormycosis in COVID-19 patients and COVID-19 recovered people is causing a debate about the therapeutics approved against COVID-19 (1-3). Several in silico studies are able to suggest possible medicines against COVID-19 even before the deposition of any solved structures for the viral proteins (4$6)$. Some of the recommended drugs are now approved by the Food and Drugs Administration (FDA) and save lives (6-8).

The viral RNA-dependent RNA polymerase (RdRp) is one of the most targeted viral proteins in many diseases caused by RNA viruses $(6,9-12)$. The active site aspartates of the RdRp is very conserved even in fungal species of Mucorales (13). On the other hand, the human Inosine monophosphate dehydrogenase (IMPDH) has been identified as a key enzyme in cell proliferation and differentiation regulation $(14,15)$. IMPDH has recently emerged as an important therapeutic target in the expedition to discover drugs belonging to the immunosuppressive, antiviral, antimicrobial, and anticancer therapeutic era. IMPDH catalyzes the de novo synthesis of purine (guanine) nucleotides, the nicotinamide adenine dinucleotide (NAD)-dependent oxidation of inosine 5-monophosphate (IMP) to xanthosine 5monophosphate (XMP). The first step of IMPDH reaction involves the attack of catalytic (Cys331) on substrate IMP followed by hydride transfer to NAD+, forming the covalent intermediate E-XMP*. E-XMP* is hydrolyzed during the second step, yielding the product XMP $(16,17)$.

Inhibition of IMPDH produces an overall reduction in guanine nucleotide pools. Subsequent interruption of DNA and RNA synthesis results in cytotoxicity inhibition of IMPDH is also used as a strategy in immuno- suppressive therapy. The growth and differentiation of human lymphocytes are particularly dependent on the IMPDH- catalyzed de novo pathway for purine nucleotide synthesis (18). Inhibition of IMPDH leads to suppression of both T and B lymphocyte proliferation. For compounds targeting the IMP- 
binding site, development has focused on the nucleotide analog. The competitive IMPDH inhibitors for IMP, such as ribavirin (19) and mizoribine (20), are nucleoside analogs that undergo phosphorylation to the active inhibitor (triphosphate) in vivo.

Thuringiensin (Thu), also known as $\beta$-exotoxin, is a thermostable secondary metabolite secreted by Bacillus thuringiensis. It has insecticidal activity against many insects, including species belonging to the orders Diptera, Coleoptera, Lepidoptera, Hymenoptera, Orthoptera, and Isoptera, and several nematode species. The insecticidal mechanism of Thu is not fully understood. However, it is known to be an ATP analog (21). The chemical formula of Thu is $\mathrm{C}_{22} \mathrm{H}_{32} \mathrm{O}_{19} \mathrm{~N}_{5} \mathrm{P}$, and it is composed of adenosine, glucose, phosphoric acid, and gluconic diacid. Thu inhibits RNA synthesis by competing with ATP on binding sites, affecting insect molting \& pupation, and causing teratological effects at sublethal doses (22-24).

In this study, our approach is to test four nucleotide inhibitors based on Thu against the RdRps of SARSCoV-2 and Rhizopus oryzae in addition to the human IMPDH. Molecular docking combined with dynamics simulation emphasizes the binding effectiveness using computational tools that are yet to be validated experimentally.

\section{Materials And Methods:}

\section{Structural retrieval and preparations}

Thuringiensin (CID: 20056441) and its analogs were retrieved from the PubChem database in the SDF format then converted to PDB using Open Babel software $(25,26)$. These analogs include Thuringiensin 6,3-Lactone (CID: 102074352), 2-[(2R,3R,4R,5S,6R)-5-[[(2R,3S,4R,5R)-5-(6-Aminopurin-9-yl)-3,4dihydroxyoxolan-2-yl]methoxy]-3,4-dihydroxy-6-(hydroxymethyl)oxan-2-yl]oxy-3,5-dihydroxy-4phosphonooxyhexanedioic acid (CID: 99213), and Adenosine 5'-(tetrahydrogentriphosphate), 5'-6-ester with D-glucose (CID: 194147). Sofosbuvir and Remdesivir are used as positive controls. AutoDock Tools 1.5.6 software was utilized to prepare the ligands for the docking (27). Kollman and Gasteiger charges were added to the ligands, and then the PDBQT files were generated for the docking experiments.

On the other hand, the three-dimensional structures of the receptors were retrieved from the Protein Data Bank (http://www.rcsb.org//pdb) (28). The selected PDB files for the SARS-CoV-2 RdRp and the human IMPDH were 7BTF and 1NF7, respectively (29). No solved structure was deposited yet for the R. oryzae $\mathrm{RdRp}$ in the protein data bank, so we used the previously in silico generated all-atoms 3D-model by the Swiss Model webserver $(13,30)$. This model was subjected to $100 \mathrm{~ns}$ MDS in a previous study and clustered through UCSF Chimera software (31). Seven different conformations of the R. oryzae model representing the most populated clusters are tested against the inhibitors. The structure 7BTF was subjected in a previous study to $100 \mathrm{~ns}$ MDS and then clustered into ten clusters (see Figure S1). We use the representative structure from each cluster to test the binding of the nucleotide inhibitors.

\section{Molecular docking}


The receptors were stored in PDB format after removing the water molecules and ligands with PyMOL software (32). Then polar hydrogen atoms and Kollman charges were added to the receptors using Autodock Tools 1.5.6 then saved in PDBQT format for the docking experiments. Autodock Vina was used for the docking of the ligands to the receptor using flexible ligands and a flexible active site protocol (33). The grid box was centered at the active residues (D760 \& D761 for SARS-CoV-2 RdRp and D193 \& D194 for R. oryzae RdRp), defined by the native co-crystallized ligands, while box size was set to $(40 \times 40 \times 40)$ $\AA^{3}$. On the other hand, the grid box size for the human IMPDH was set to be $(40 \times 60 \times 64) \AA^{3}$ and centered at $(76.7,83.8,53.9)$. The active site for the human IMPDH was S68, N303, R322, S388, Y411, M414, and Q441. Other docking parameters were set to default while the exhaustiveness value was adjusted to 8 in all the docking trials. Discovery studio software is utilized to analyze the docking complexes (34).

\section{Results And Discussion}

In the current study, four nucleotide inhibitors are tested against both host-cell (Inosine monophosphate dehydrogenase) and pathogen's proteins (RNA-dependent RNA polymerase). These proteins proved their effectiveness as drug targets $(6,13,35,36)$. Figure 1 shows the 2D structures of the four nucleotide inhibitors which are Thuringiensin derivatives (CID: 99213, 194147, 20056441, and 102074352) and the positive control drugs (Sofosbuvir and Remdesivir). The FDA approves these drugs against RNA viruses such as Hepatitis C Virus, Ebola virus, and SARS-CoV-2 (37-41). The four Thuringiensin derivatives are based on the nucleotide adenosine $(A)$, where the added moieties are present at the 5 ' position of the ribose ring. On the other hand, the positive controls drugs (remdesivir and Sofosbuvir) are adenosine triphosphate modified at position 1' of the ribose $(C \equiv N)$ and uridine derivative modified at position 1 ' of the ribose ( $F$, methyl), respectively.

\section{Binding affinities of the nucleotide inhibitors against the pathogenic proteins}

As shown in Fig. 2, the average binding affinities of the four nucleotide inhibitors (blue columns) (CID: 99213, 194147, 20056441, and 102074352) against SARS-CoV-2 RdRp (A), Rhizopus oryzae RdRp (B), and the human IMPDH (C) are in the same range of the positive control drugs. In Fig. 2, the error bars represent the standard deviations. Red columns in Fig. 2 represent the positive control drugs (Sofosbuvir and Remdesivir). The docking trials are performed on different conformations of the RdRp proteins generated from the 100 ns MDS runs, while Each conformation resembles a cluster from the trajectories. The MDS's role was to equilibrate the protein systems and ensure different possible conformations during the simulation period.

The average binding affinity for the four nucleotide inhibitors lies between $-6.84 \mathrm{kcal} / \mathrm{mol}(194147$ versus SARS-CoV-2 RdRp) and $-9.8 \mathrm{kcal} / \mathrm{mol}$ (102074352 versus human IMPDH). For the SARS-CoV-2 $\mathrm{RdRp}$, the average binding affinity for the four nucleotide inhibitors is $-7.24 \mathrm{kcal} / \mathrm{mol}$, while the average binding affinities of sofosbuvir and remdesivir against SARS-CoV-2 RdRp are -7.4 and $-7.3 \mathrm{kcal} / \mathrm{mol}$, 
respectively. Additionally, the average binding affinity of the four nucleotide inhibitors against R. oryzae $\mathrm{RdRp}$ is $-7.63 \mathrm{kcal} / \mathrm{mol}$, while it is -8.06 and $-7.8 \mathrm{kcal} / \mathrm{mol}$ for the sofosbuvir and remdesivir, respectively. These values indicate that the Thuringiensin derivatives have comparable average binding affinities to that of Sofosbuvir and Remdesivir against the viral and fungal RdRps.

On the other hand, the average binding affinity of the four nucleotide inhibitors against the human IMPDH is $-8.71 \mathrm{kcal} / \mathrm{mol}$, which is lower (better) than the average binding affinity of the positive controls (-8.3 and $-7.85 \mathrm{kcal} / \mathrm{mol}$ for sofosbuvir and remdesivir, respectively). The best compound from the Thuringiensin derivatives in binding all the proteins is the Thuringiensin 6,3-lactone (CID: 102074352). In order to check the binding mode of each ligand to the three proteins, the interaction map of the complexes is mined by the Discovery studio software. Based on the analysis, the compounds' binding modes against SARS-CoV-2 RdRp, R. oryzae RdRp, and human IMPDH are explored and tabulated.

Table 1 lists the interactions established for each ligand (Thuringiensin derivatives and the positive control drugs) after docking to the active site of the proteins. The main type of interaction that formed upon docking is the formation of Hydrogen bonds (H-bonds). An average of $13 \mathrm{H}$-bonds is formed between the positive control drugs and the protein. For the Thuringiensin derivatives, the average number of $\mathrm{H}$-bonds formed is 14 , while few hydrophobic contacts, salt bridges (red), and halogen bonds (green) are reported in Table 1. The residues shown in bold are the active site residues in each protein. For example, the most-reported residues from SARS-CoV-2 RdRp that take part in the interactions with the nucleotide inhibitors are D760(12), D761(9), D618(9), R555(8), E811(6), S814(6), and Y619(5), ranked by the number of reported interaction established upon docking. For the R. oryzae RdRp, the most reported residues to interact with the fungal RdRp are E27(15), D56(12), R14(10), D193(8), G142(5), S146(5), D194(5). On the other hand, the residues from the human IMPDH that reported to interact with the nucleotide inhibitors are D364(14), D274(12), S276(8), H93(6), G326(6), D256(5), C331(5), and T333(5). 
Table 1

The interactions that were established after docking the four adenosine derivatives and positive controls (Sofosbuvir and Remdesivir) into the SARS-CoV-2 RdRp, Rhizopus oryzae RdRp, and the human IMPDH. Red-colored residues are residues that interact with salt bridges, while green-colored residues are that interact through halogen bonds. Bold residues are the active residues in each protein.

\begin{tabular}{|c|c|c|c|c|c|c|}
\hline \multirow[t]{2}{*}{$\begin{array}{l}\text { Protein } \\
\text { target }\end{array}$} & \multirow[t]{2}{*}{ Compound } & \multirow{2}{*}{$\begin{array}{l}\text { Binding } \\
\text { affinity } \\
\text { (kcal/mol) }\end{array}$} & \multicolumn{2}{|c|}{ H-bonding } & \multicolumn{2}{|c|}{$\begin{array}{l}\text { Hydrophobic } \\
\text { interaction }\end{array}$} \\
\hline & & & number & Amino acids involved & number & $\begin{array}{l}\text { Amino } \\
\text { acids } \\
\text { involved }\end{array}$ \\
\hline \multirow[t]{6}{*}{$\begin{array}{l}\text { SARS- } \\
\text { CoV-2 } \\
\text { RdRp }\end{array}$} & Sofosbuvir & -7.4 & 8 & $\begin{array}{l}\text { S549, R555(2), R555, } \\
\text { Y619, K621, C622, D623, } \\
\text { and N691 }\end{array}$ & & \\
\hline & Remdesivir & -7.3 & 10 & $\begin{array}{l}\text { K551, R555(2), D618, } \\
\text { Y619, K621, K621, } \\
\text { D760(4), D761(2), and } \\
\text { S814 }\end{array}$ & 1 & K551 \\
\hline & CID: 99213 & -7.4 & 11 & $\begin{array}{l}\text { D618(4), Y619, C622, } \\
\text { D761(2), W800, and } \\
\text { E811(2) }\end{array}$ & & \\
\hline & $\begin{array}{l}\text { CID: } \\
194147\end{array}$ & -6.9 & 14 & $\begin{array}{l}\text { K551(3), R555, W617, } \\
\text { Y619(2), D760, W800, } \\
\text { E811(2), S814(2), and } \\
\text { R836 }\end{array}$ & & \\
\hline & $\begin{array}{l}\text { CID: } \\
20056441\end{array}$ & -7.1 & 18 & $\begin{array}{l}\text { R555(2), D618(3), D623, } \\
\text { D760(6), D761(4), and } \\
\text { S814(2) }\end{array}$ & & \\
\hline & $\begin{array}{l}\text { CID: } \\
102074352\end{array}$ & -7.4 & 8 & $\begin{array}{l}\text { K551, D618, D760, D761, } \\
\text { W800, E811(2), and S814 }\end{array}$ & & \\
\hline \multirow[t]{5}{*}{$\begin{array}{l}\text { Rhizopus } \\
\text { oryzae } \\
\text { RdRp }\end{array}$} & Sofosbuvir & -8.0 & 11 & $\begin{array}{l}\text { P10, R14, Q141(2), S146, } \\
\text { D193(3), and D194(3) }\end{array}$ & 4 & $\begin{array}{l}\text { A11, } \\
\text { Y13(2), } \\
\text { and } \\
\text { Y150 }\end{array}$ \\
\hline & Remdesivir & -7.9 & 11 & $\begin{array}{l}\text { E27(2), Q31, S53, D56(2), } \\
\text { Y191, D193(2), and } \\
\text { D194(2) }\end{array}$ & 5 & $\begin{array}{l}\text { N12, } \\
\text { R14, } \\
\text { and } \\
\text { E27(3) }\end{array}$ \\
\hline & CID: 99213 & -7.1 & 17 & $\begin{array}{l}\text { R14(2), E27(5), D56(4), } \\
\text { Y88, G142, S146(3), and } \\
\text { D193 }\end{array}$ & & \\
\hline & $\begin{array}{l}\text { CID: } \\
194147\end{array}$ & -7.2 & 15 & $\begin{array}{l}\text { R14(3), E27(2), D56(4), } \\
\text { Q57, G142(2), S143(2), } \\
\text { and Y191 }\end{array}$ & & \\
\hline & $\begin{array}{l}\text { CID: } \\
20056441\end{array}$ & -7.5 & 15 & $\begin{array}{l}\mathrm{R} 14(2), \mathrm{D} 83(2), \mathrm{S} 86(2), \\
\text { Y88, T90, G142(2), }\end{array}$ & 1 & W222 \\
\hline
\end{tabular}


P147(2), D193(2), and

W222

\begin{tabular}{|c|c|c|c|c|c|c|}
\hline & $\begin{array}{l}\text { CID: } \\
102074352\end{array}$ & -8.3 & 12 & $\begin{array}{l}\text { Y13, R14, E27(3), D56(2), } \\
\text { Y88, Q141(2), S143, and } \\
\text { S146 }\end{array}$ & & \\
\hline \multirow[t]{6}{*}{$\begin{array}{l}\text { Human } \\
\text { IMPDH }\end{array}$} & Sofosbuvir & -8.0 & 15 & $\begin{array}{l}\text { D274(2), S276(2), M325, } \\
\text { G326, S327, G328, C331, } \\
\text { D364(4), G415(2), K438, } \\
\text { and G442 }\end{array}$ & & \\
\hline & Remdesivir & -7.8 & 23 & $\begin{array}{l}\text { D274(4), S276(3), R322, } \\
\text { G324(2), M325(2), } \\
\text { G326(2), S327, C331, } \\
\text { D364(2), M414, G415, } \\
\text { K438(2), and Q441 }\end{array}$ & 1 & D274 \\
\hline & CID: 99213 & -8.4 & 12 & $\begin{array}{l}\text { S68(2), D256(2), D274, } \\
\text { S276, R322, G326, C331, } \\
\text { T333, and D364(2) }\end{array}$ & & \\
\hline & $\begin{array}{l}\text { CID: } \\
194147\end{array}$ & -7.3 & 17 & $\begin{array}{l}\text { S68, H93, D274(4), } \\
\text { S275(2), S276, G326, } \\
\text { S327, C331, T333, and } \\
\text { D364(4) }\end{array}$ & & \\
\hline & $\begin{array}{l}\text { CID: } \\
20056441\end{array}$ & -8.3 & 15 & $\begin{array}{l}\mathrm{H} 93(2), \mathrm{N} 94, \mathrm{D} 256(2), \\
\mathrm{R} 259, \mathrm{~S} 276, \mathrm{~N} 303, \\
\text { G324(2), G326, S327, } \\
\text { T333(2), and D364 }\end{array}$ & 3 & $\mathrm{H} 93(3)$ \\
\hline & $\begin{array}{l}\text { CID: } \\
102074352\end{array}$ & -9.8 & 11 & $\begin{array}{l}\text { T252(2), D256, S275(2), } \\
\text { Q277, N303, R322, C331, } \\
\text { T333, and D364 }\end{array}$ & & \\
\hline
\end{tabular}

Figure 3 shows the interactions that established between Thuringiensin 6,3-lactone (CID: 102074352), and the SARS-CoV-2 RdRp (top left), R. oryzae RdRp (top write), and the human IMPDH (down). This compound shows the best average binding affinities against the three proteins (see Fig. 2) compared to other nucleotide inhibitors. Figure 3 is represented by Discovery studio software, where the ligand is shown in the sticks, and the interacting residues are depicted in lines. The only type of interaction is the formation of H-bonds (dashed lines). Thuringiensin 6,3-lactone (CID: 102074352) formed $8 \mathrm{H}$-bonds to SARS-CoV-2 RdRp with residues K551, D618, D760, D761, W800, E811(2), and S814. For R. oryzae RdRp Y13, R14, E27(3), D56(2), Y88, Q141(2), S143, and S146 formed 12 H-bonds with Thuringiensin 6,3lactone. At the same time, residues T252(2), D256, S275(2), Q277, N303, R322, C331, T333, and D364 of the human IMPDH formed $11 \mathrm{H}$-bonds with Thuringiensin 6,3-lactone.

The current work reveals the favorable binding affinity of four adenosine derivatives against the SARSCoV-2 RdRp, Rhizopus oryzae RdRp, and the human IMPDH. Thuringiensin 6,3-lactone has the best binding affinity to the three proteins, hence can be a potential inhibitor against COVID-19/Mucormycosis coinfection, while experimental validation is yet to be performed. 


\section{Conclusion:}

Remdesivir proves its effectiveness against COVID-19 (reducing the hospitalization time). Four Thuringiensin derivatives (adenosine based) are tested against SARS-CoV-2 RdRp, Rhizopus oryzae RdRp, and the human IMPDH using in silico techniques. The results reveal the binding potential of the Thuringiensin derivatives against the viral, fungal, and human proteins. These adenosine derivatives can be potential inhibitors of the dual SARS-CoV-2 (COVID-19) R. oryzae (Mucormycosis) coinfection. Further, in vitro and other experimental validations are suggested for the best compound (Thuringiensin 6,3lactone) as future work.

\section{Declarations}

\section{Conflict of interest:}

All the authors declare no conflict of interest in this work.

\section{Authors' contribution:}

A.H. own the idea, wrote the methods, and revised the manuscript. A.E. \& A.E. drafted the manuscript, make calculations, and generated figures and tables. All the authors wrote and approved the final draft of the manuscript.

\section{Acknowledgment:}

Bibliotheca Alexandrina is used to performing the MDS calculations. This work is supported by the Cairo University COVID-19 fund received by A.E.

\section{References}

1. Werthman-Ehrenreich A (2021) Mucormycosis with orbital compartment syndrome in a patient with COVID-19. Am J Emerg Med 42:264 e5-e8

2. Vaidyanathan G. Coronavirus variants are spreading in India-what scientists know so far. Nature. $2021 ; 332$

3. Mahmud S, Elfiky AA, Amin A, Mohanto SC, Rahman E, Acharjee UK et al (2021) Targeting SARS-CoV2 nonstructural protein 15 endoribonuclease: an in silico perspective. Future Virol 0(0):null

4. Elfiky AA, Ibrahim IM, Amin FG, Ismail AM, Elshemey WM (2021) COVID-19 and Cell Stress. Adv Exp Med Biol 1318:169-178

5. Ibrahim IM, Abdelmalek DH, Elshahat ME, Elfiky AA (2020) COVID-19 spike-host cell receptor GRP78 binding site prediction. J Infect 80(5):554-562

6. Sonousi A, Mahran HA, Ibrahim IM, Ibrahim MN, Elfiky AA, Elshemey WM. Novel adenosine derivatives against SARS-CoV-2 RNA-dependent RNA polymerase: an in silico perspective. Pharmacol Rep. 2021 
7. Beigel JH, Tomashek KM, Dodd LE, Mehta AK, Zingman BS, Kalil AC et al. Remdesivir for the treatment of Covid-19-preliminary report. New England Journal of Medicine. 2020

8. Beigel JH, Tomashek KM, Dodd LE, Mehta AK, Zingman BS, Kalil AC et al (2020) Remdesivir for the treatment of Covid-19. N Engl J Med 383(19):1813-1826

9. Elfiky AA, Ismail A (2019) Molecular dynamics and docking reveal the potency of novel GTP derivatives against RNA dependent RNA polymerase of genotype 4a HCV. Life Sci 238:116958

10. Elfiky AA, Elshemey WM (2018) Molecular dynamics simulation revealed binding of nucleotide inhibitors to ZIKV polymerase over 444 nanoseconds. J Med Virol 90(1):13-18

11. Abdo AE (2019) Novel Guanosine Derivatives as Anti-HCV NS5b Polymerase: A QSAR and Molecular Docking Study. Med Chem 15(2):130-137

12. Elfiky AA (2020) Novel guanosine derivatives against Zika virus polymerase in silico. J Med Virol 92(1):11-16

13. Elfiky AA (2019) The antiviral Sofosbuvir against mucormycosis: an in silico perspective. Future Virology 14(11):739-744

14. Weber G, Prajda N, Abonyi M, Look KY, Tricot G (1996) Tiazofurin: molecular and clinical action. Anticancer Res 16(6A):3313-3322

15. Wu JC (1994) Mycophenolate mofetil: molecular mechanisms of action. Perspectives in drug discovery design 2(1):185-204

16. Weber G, Prajda N, Jackson RC (1976) Key enzymes of IMP metabolism: transformation and proliferation-linked alterations in gene expression. Adv Enzyme Regul 14:3-24

17. Hedstrom L, Wang CC (1990) Mycophenolic acid and thiazole adenine dinucleotide inhibition of Tritrichomonas foetus inosine 5'-monophosphate dehydrogenase: implications on enzyme mechanism. Biochemistry 29(4):849-854

18. Allison AC, Hovi T, Watts RW, Webster AD. The role of de novo purine synthesis in lymphocyte transformation. Ciba Found Symp. 1977(48):207 - 24

19. Striepen B, Pruijssers AJ, Huang J, Li C, Gubbels MJ, Umejiego NN et al (2004) Gene transfer in the evolution of parasite nucleotide biosynthesis. Proc Natl Acad Sci U S A 101(9):3154-3159

20. Chen L, Wilson DJ, Xu Y, Aldrich CC, Felczak K, Sham YY et al (2010) Triazole-linked inhibitors of inosine monophosphate dehydrogenase from human and Mycobacterium tuberculosis. Journal of medicinal chemistry 53(12):4768-4778

21. Farkaš J, Šebesta K, Horska K, Samek Z, Dolejš L, Šorm F (1969) The structure of exotoxin of Bacillus thuringiensis var. gelechiae. Preliminary communication. Collect Czech Chem Commun 34(3):1118-1120

22. Šebesta K, Horska K. Mechanism of inhibition of DNA-dependent RNA polymerase by exotoxin of Bacillus thuringiensis. Biochimica et Biophysica Acta (BBA)-Nucleic Acids and Protein Synthesis. 1970;209(2):357-67 
23. Burgerjon A, Biache G, Cals P (1969) Teratology of the Colorado potato beetle, Leptinotarsa decemlineata, as provoked by larval administration of the thermostable toxin of Bacillus thuringiensis. J Invertebr Pathol 14(2):274-278

24. Ignoffo C, Gregory B (1972) Effects of Bacillus thuringiensis $\beta$-exotoxin on larval maturation, adult longevity, fecundity, and egg viability in several species of Lepidoptera. Environ Entomol 1(3):269272

25. Kim S, Thiessen PA, Bolton EE, Chen J, Fu G, Gindulyte A et al (2016) PubChem Substance and Compound databases. Nucleic Acids Res 44(D1):D1202-D1213

26. O'Boyle NM, Banck M, James CA, Morley C, Vandermeersch T, Hutchison GR (2011) Open Babel: An open chemical toolbox. J Cheminform 3(1):33

27. Morris GM, Huey R, Lindstrom W, Sanner MF, Belew RK, Goodsell DS et al (2009) AutoDock4 and AutoDockTools4: Automated docking with selective receptor flexibility. J Comput Chem 30(16):2785-2791

28. Berman H, Henrick K, Nakamura H (2003) Announcing the worldwide Protein Data Bank. Nat Struct Biol 10(12):980

29. Gao Y, Yan L, Huang Y, Liu F, Zhao Y, Cao L et al (2020) Structure of the RNA-dependent RNA polymerase from COVID-19 virus. Science 368(6492):779-782

30. Biasini M, Bienert S, Waterhouse A, Arnold K, Studer G, Schmidt T et al. SWISS-MODEL: modelling protein tertiary and quaternary structure using evolutionary information. Nucleic Acids Res. 2014;42(Web Server issue):W252-8

31. Pettersen EF, Goddard TD, Huang CC, Couch GS, Greenblatt DM, Meng EC et al (2004) UCSF Chimera -a visualization system for exploratory research and analysis. J Comput Chem 25(13):1605-1612

32. 2.4.1 V. The PyMOL Molecular Graphics System, Version 2.4.1 Schrödinger, LLC. [

33. Trott O, Olson AJ (2010) AutoDock Vina: improving the speed and accuracy of docking with a new scoring function, efficient optimization, and multithreading. J Comput Chem 31(2):455-461

34. Jejurikar BL, Rohane SH (2021) Drug Designing in Discovery Studio. Asian Journal of Research in Chemistry 14(2):135-138

35. Elfiky AA, Azzam EB, Shafaa MW. The anti-HCV, Sofosbuvir, versus the anti-EBOV Remdesivir against SARS-CoV-2 RNA dependent RNA polymerase in silico. Molecular Diversity. 2020

36. Trapero A, Pacitto A, Singh V, Sabbah M, Coyne AG, Mizrahi V et al (2018) Fragment-Based Approach to Targeting Inosine-5'-monophosphate Dehydrogenase (IMPDH) from Mycobacterium tuberculosis. Journal of medicinal chemistry 61(7):2806-2822

37. Elfiky AA, Elshemey WM (2018) Molecular dynamics simulation revealed binding of nucleotide inhibitors to ZIKV polymerase over 444 nanoseconds. J Med Virol 90(1):13-18

38. Elfiky AA (2017) Zika virus: novel guanosine derivatives revealed strong binding and possible inhibition of the polymerase. Future Virology 12(12):721-728 
39. Elfiky AA, Ismail A (2019) Molecular dynamics and docking reveal the potency of novel GTP derivatives against RNA dependent RNA polymerase of genotype 4a HCV. Life Sci 238:116958

40. Elfiky AA. Novel Guanosine Derivatives as Anti-HCV NS5b Polymerase: A QSAR and Molecular Docking Study. Medicinal chemistry (Shariqah (United Arab Emirates)). 2019;15(2):130-7

41. Adem S, Eyupoglu V, Sarfraz I, Rasul A, Zahoor AF, Ali M et al (2021) Caffeic acid derivatives (CAFDs) as inhibitors of SARS-CoV-2: CAFDs-based functional foods as a potential alternative approach to combat COVID-19. Phytomedicine 85:153310

\section{Figures}

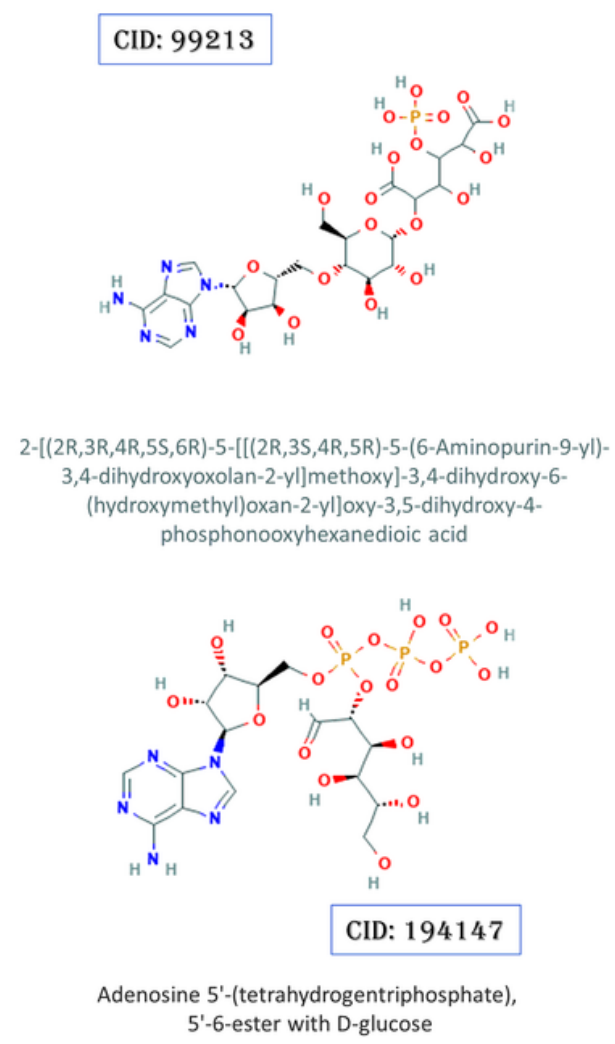

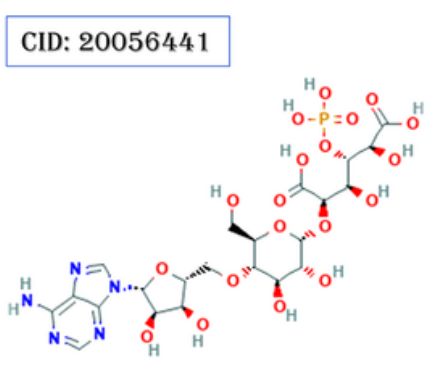

Thuringiensin

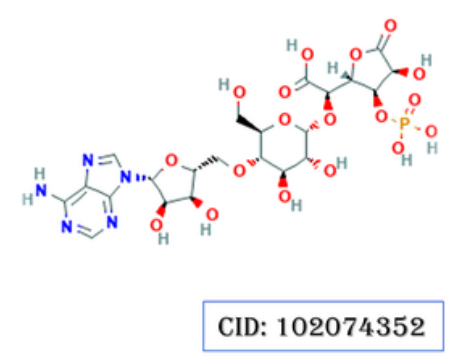

Thuringiensin 6,3-lactone

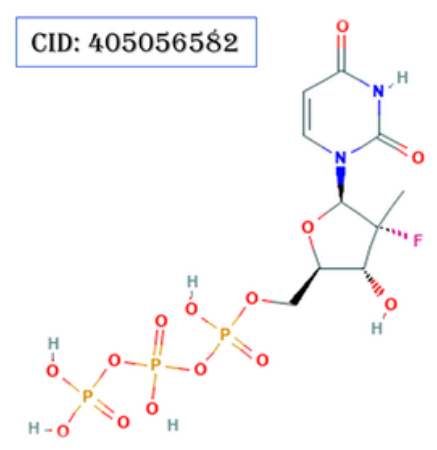

Sofosbuvir triphosphate

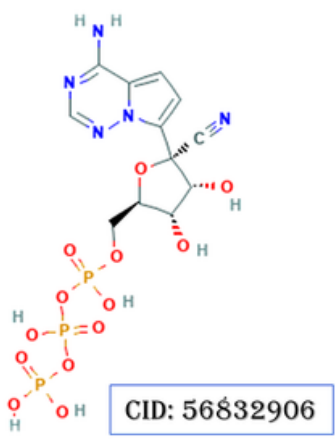

Remdesivir triphosphate

\section{Figure 1}

2D structures show the four Thuringiensin derivatives and the positive control drugs Sofosbuvir and Remdesivir with PubChem accession numbers. 
A

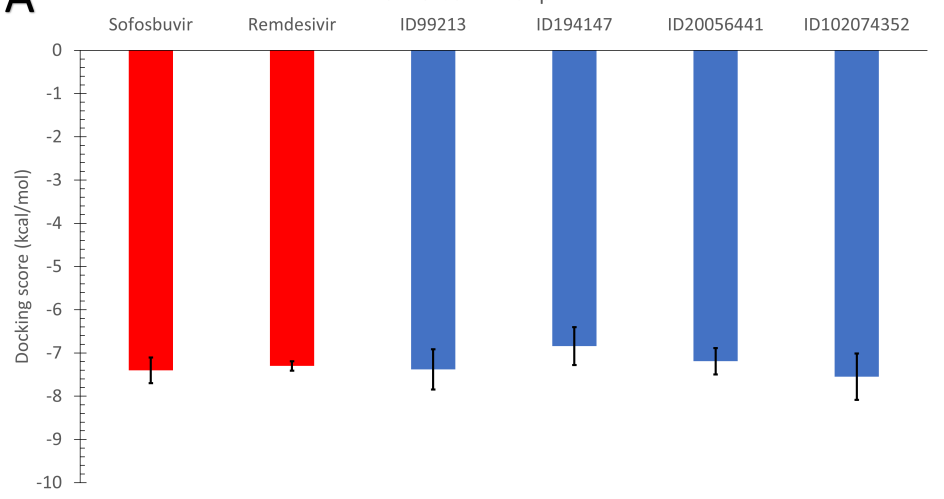

B

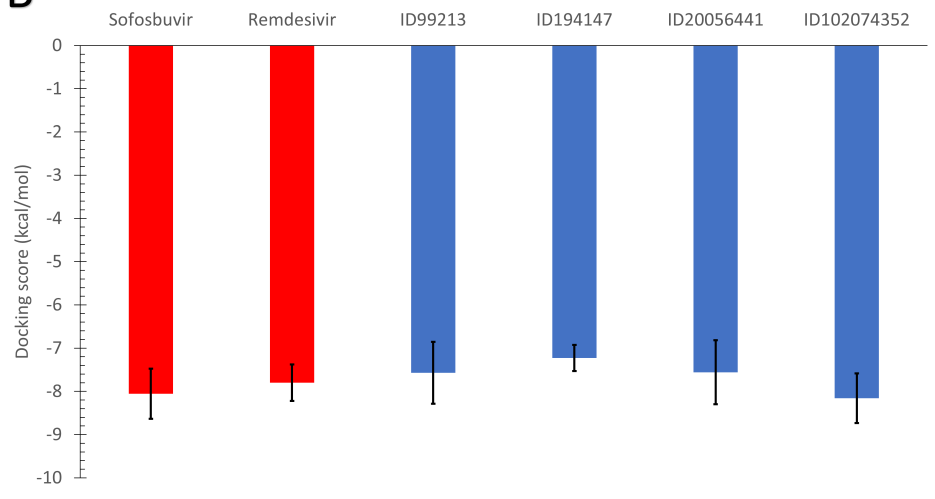

C

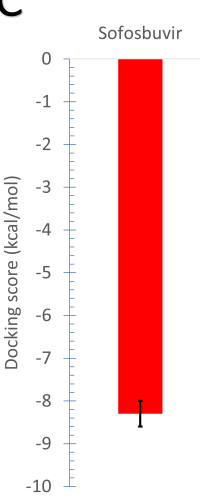

human IMPDH

ID99213

ID194147

ID20056441

ID102074352
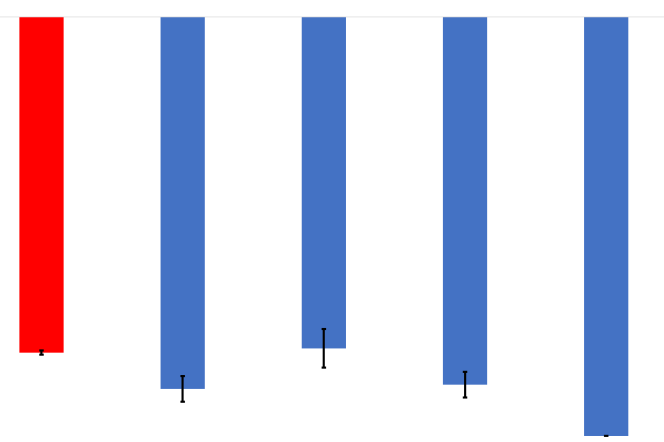

\section{Figure 2}

The average binding affinities (in $\mathrm{kcal} / \mathrm{mol}$ ) for the four adenosine derivatives (blue columns) and the positive controls (red columns) against (A) SARS-CoV-2 RdRp, (B) Rhizopus oryzae RdRp, and (C) the human IMPDH. Error bars resemble the standard deviation (SD) of the mean. Different conformations of the proteins are used in the docking experiments after MDS cluster analysis. 


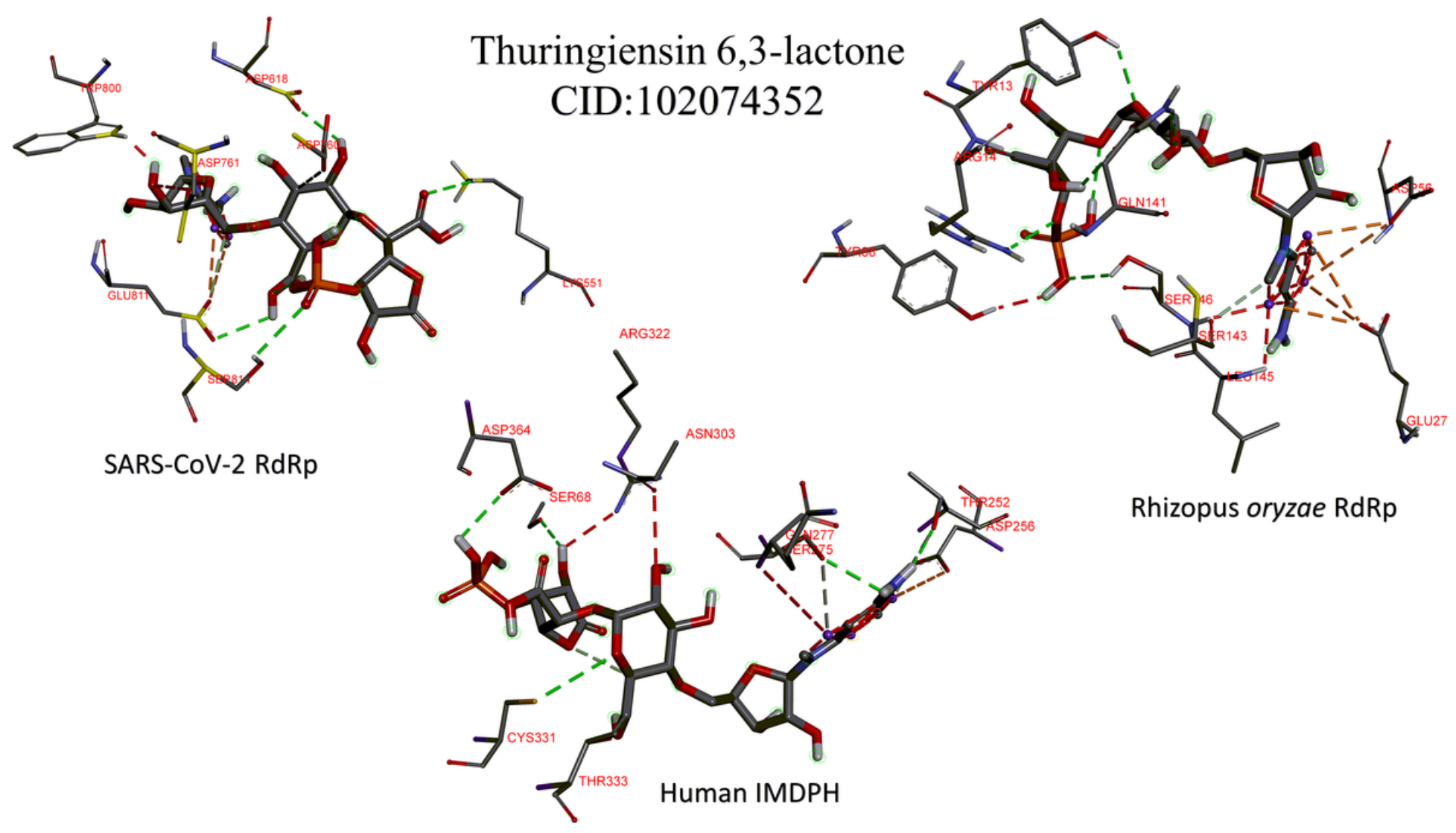

Figure 3

The interaction patterns for the best adenosine derivative (Thuringiensin 6,3-lactone) after docking into the active site of SARS-CoV-2 RdRp (top left), Rhizopus oryzae RdRp (top right), and the human IMPDH (bottom). The residues from the proteins that form contacts to the ligands are depicted in lines, while the ligands are in the sticks. H-bonds are shown in dashed lines.

\section{Supplementary Files}

This is a list of supplementary files associated with this preprint. Click to download.

- FigureS1A.tif

- FigureS1B.tif

- Figures1C.tif 